\title{
Effects of laser power density on static and dynamic mechanical properties of dissimilar stainless steel welded joints
}

\author{
Yan-Peng Wei · Mao-Hui Li · Gang Yu • Xian-Qian Wu • Chen-Guang Huang • Zhu-Ping Duan
}

Received: 14 June 2011 / Revised: 21 September 2011 / Accepted: 20 February 2012

(C)The Chinese Society of Theoretical and Applied Mechanics and Springer-Verlag Berlin Heidelberg 2012

\begin{abstract}
The mechanical properties of laser welded joints under impact loadings such as explosion and car crash etc. are critical for the engineering designs. The hardness, static and dynamic mechanical properties of AISI304 and AISI316 L dissimilar stainless steel welded joints by $\mathrm{CO}_{2}$ laser were experimentally studied. The dynamic strainstress curves at the strain rate around $10^{3} \mathrm{~s}^{-1}$ were obtained by the split Hopkinson tensile bar (SHTB). The static mechanical properties of the welded joints have little changes with the laser power density and all fracture occurs at $316 \mathrm{~L}$ side. However, the strain rate sensitivity has a strong dependence on laser power density. The value of strain rate factor decreases with the increase of laser power density. The
\end{abstract}

The project was supported by the National Natural Science Foundation of China (10832011).

Y.-P. Wei (困) · X.-Q. Wu • C.-G. Huang

Key Laboratory of Hydrodynamics and Ocean Engineering, Institute of Mechanics, Chinese Academy of Sciences, 100190 Beijing, China

e-mail: weiyanpeng@imech.ac.cn

\section{M.-H. Li}

The Quartermaster Equipment Research Institute of the General Logistics Department of PLA, 100010 Beijing, China

\section{G. Yu}

Key Lab of Mechanics in Advanced Manufacturing, Institute of Mechanics, Chinese Academy of Sciences, 100190 Beijing, China

\section{Z.-P. Duan}

The State Key Laboratory of Nonlinear Mechanics, Institute of Mechanics, Chinese Academy of Sciences, 100190 Beijing, China welded joint which may be applied for the impact loading can be obtained by reducing the laser power density in the case of welding quality assurance.

Keywords Laser welding · Dynamic mechanics · Strain rate - Power density

\section{Introduction}

Due to its excellent mechanical properties, superior corrosion resistance, and the ease with which it may be formed and welded, austenitic stainless steel has been widely used as structural materials throughout the automotive and chemical industries and within nuclear power plants [1-5]. In practical applications, weldments of dissimilar stainless steels are often used. Stainless steel components can be joined by means of a variety of welding methods, among which laser welding has drawn particular attention due to its high welding speed, narrow heat affected zone, low residual stress and small distortion of welded materials [6-8]. In automotive and defense applications, the structures with welded joints are often subjected to high strain rate deformation in service such as car crash, explosion and the impact of foreign objects. Therefore, the design of the structure consisting of these welded components calls for a detailed understanding of the mechanical properties of these weldments, especially the dynamic mechanical behavior. Many researches had been carried out concerning mechanical properties of stainless steel and their welded joints. Bayraktar et al. [9-11] developed the impact tensile testing technique to study the impact resistance of laser welded thin sheets of different steel grades at different temperatures. The resulted ductile/brittle temperature diagram allows explaining pure damage mechanism of the each part of the welded components in the case of the crash. They also obtained the dynamic fracture energy at the strain rate $250 \mathrm{~s}^{-1}$. Xu and Li [12] studied the dynamic compression behavior of the base metal and the weld metal for 
the welded joints of $0 \mathrm{Cr} 18 \mathrm{Ni} 10 \mathrm{Ti}$ austenitic stainless steel by using a Hopkinson pressure bar system. However, little work has been reported with regard to dynamic tensile behavior of laser welded joints of austenitic stainless steel. Split Hopkinson pressure/tensile bar (SHP/TB) has been widely applied to obtain the dynamic tensile stress-strain curve of materials at strain rates $10^{2}-10^{4} \mathrm{~s}^{-1}[13-16]$. In this study, an improved split Hopkinson tensile bar (SHTB) device was used to evaluate the dynamic mechanical properties of the laser welded joints of 304 and $316 \mathrm{~L}$ stainless steel at strain rates $10^{3} \mathrm{~s}^{-1}$. The effects of laser power density on hardness, static and dynamic mechanical properties were studied. The Johnson-Cook models [17] are used to describe the experimental stress-strain curves. The dependence of the strain rate sensitivity of the plastic flow stress on laser welding parameters is reported, which would provide useful information for the engineering design of the structure consisting of laser welded joints.

\section{Experiment}

Sheet materials of a 304 stainless steel $0 \mathrm{Cr} 18 \mathrm{Ni} 9(2 \mathrm{~mm}$ in thickness) and a $316 \mathrm{~L}$ stainless steel $0 \mathrm{Cr} 17 \mathrm{Ni} 14 \mathrm{Mo} 2(2 \mathrm{~mm}$ in thickness) were selected as the base materials for laser welding. The chemical composition and static mechanical properties of sheet materials are shown in Tables 1 and 2, respectively. A diffusion cooled slab $3.5 \mathrm{~kW} \mathrm{CO}$ laser was used to weld the joint. The laser beam with Gaussian mode $(K \geq 0.95)$ and a wavelength of $10.6 \mu \mathrm{m}$ was used. The laser beam was focused by using a copper mirror of a focus length $300 \mathrm{~mm}$. The welding area is shielded with He gas at a flow rate of $10 \mathrm{~L} / \mathrm{min}$. To avoid the distortion, a fixture was used to fix the stainless steel sheet (as shown in Fig. 1). Five laser welding processes with different laser power densities were carried out as shown in Table 3 . The laser power density $D$ is defined as

$D=\frac{P}{v \phi}$

where $P$ is the laser power, $v$ is the welding speed and $\phi$ is the diameter of the focused laser spot. By changing the defocus and welding speed, the laser power density varies from $39.4-64.3 \mathrm{~kW} / \mathrm{cm}^{2}$.

Table 1 Chemical composition of AISI304 and AISI316 L

\begin{tabular}{|c|c|c|c|c|c|c|c|c|}
\hline Grade & $\mathrm{C}$ & $\mathrm{Cr}$ & $\mathrm{Ni}$ & $\mathrm{Mn}$ & $\mathrm{P}$ & $\mathrm{S}$ & Mo & $\mathrm{Si}$ \\
\hline AISI304 & 0.07 & $17-19$ & $8-10$ & 2.0 & 0.035 & 0.030 & 0 & 0.1 \\
\hline AISI316L & 0.03 & $16-18$ & $12-16$ & 2.0 & 0.030 & 0.030 & $1.8-2.5$ & 0.1 \\
\hline
\end{tabular}

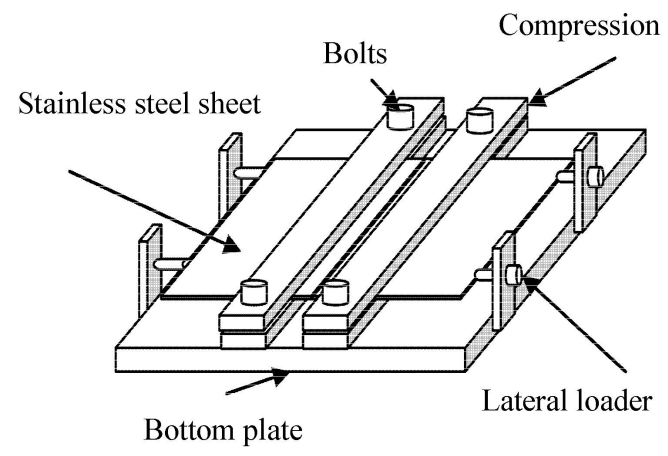

Fig. 1 A fixture used to fix the stainless steel sheet during laser welding

Table 2 Static mechanic properties of AISI304 and AISI316L

\begin{tabular}{lllll}
\hline Grade & Elastic modulus/GPa & Yield strength/MPa & UTS/MPa & Elongation/\% \\
\hline AISI304 & 205 & 246 & 630 & 67 \\
AISI316L & 205 & 234 & 551 & 58 \\
\hline
\end{tabular}

Table 3 Laser welding parameters

\begin{tabular}{llllll}
\hline No. & Laser power $/ \mathrm{kW}$ & Defocus $/ \mathrm{mm}$ & Welding speed $/\left(\mathrm{m} \cdot \mathrm{s}^{-1}\right)$ & Spot diameter $/ \mu \mathrm{m}$ & Power density $/\left(\mathrm{kW} \cdot \mathrm{cm}^{-2}\right)$ \\
\hline 1 & 3.5 & -2 & 3.0 & 272 & 42.9 \\
2 & 3.5 & -3 & 3.0 & 296 & 39.4 \\
3 & 3.5 & -2 & 2.0 & 272 & 64.3 \\
4 & 3.0 & -2 & 2.0 & 272 & 55.1 \\
5 & 3.0 & -2 & 2.5 & 272 & 51.4 \\
\hline
\end{tabular}

The microstructure was investigated by using a POLYVAR metallographic microscope. Prior to observation, the specimens were sectioned and ground and then etched in a solution of 3 parts $\mathrm{HCl}$ and 1 part $\mathrm{HNO}_{3}$ for approximately $15 \mathrm{~s}$.

In order to identify the possible effects of microstruc- 
ture heterogeneities both in the weld bead and in the base metal, microhardness surveys were carried out by using a Zwick Vickers hardness tester at $100 \mathrm{~g}$ load for $20 \mathrm{~s}$. The microhardness tests were performed on the sectional surface of the weldment.

The quasi-static uniaxial tensile experiment was carried out by using an MTS810 system with a $25 \mathrm{kN}$ load cell. The strain was measured by an extensometer and the gauge length is initially $10 \mathrm{~mm}$. The strain rate during tensile experiments is $10^{-3} \mathrm{~s}^{-1}$. The dynamic mechanical properties of the laser welded joints were investigated at strain rates $10^{3} \mathrm{~s}^{-1}$ with an improved SHTB device. Figure 2 shows a schematic representation of the specimen and their dimensions for both the static and dynamic tests. The dynamic tensile specimen had a special design to fit the SHTB slot in the elastic input and output bar. The gauge region consists of a weld bead sandwiched by base metals. The tensile test was performed to be perpendicular to the direction of the weld bead. The tensile specimen was firstly cut from the weldment, and then ground and polished to remove materials from the front and back surfaces to ensure that the welded bead has a relatively uniform width in the thickness direction.

For the dynamic tensile test, based on the one dimension stress wave theory, the average strain, strain rate and stress can be calculated from Eqs. (2)-(4) with strain signals which were derived from the strain gauges located at the elastic input and output bar, where

$$
\begin{aligned}
& \dot{\varepsilon}(t)=\frac{C_{0}}{L}\left(\varepsilon_{I}(t)-\varepsilon_{R}(t)-\varepsilon_{T}(t)\right), \\
& \varepsilon(t)=\frac{C_{0}}{L} \int_{0}^{t}\left(\varepsilon_{I}(t)-\varepsilon_{R}(t)-\varepsilon_{T}(t)\right) \mathrm{d} t, \\
& \sigma(t)=\frac{A E}{2 A_{0}}\left(\varepsilon_{I}(t)+\varepsilon_{R}(t)+\varepsilon_{T}(t)\right)
\end{aligned}
$$

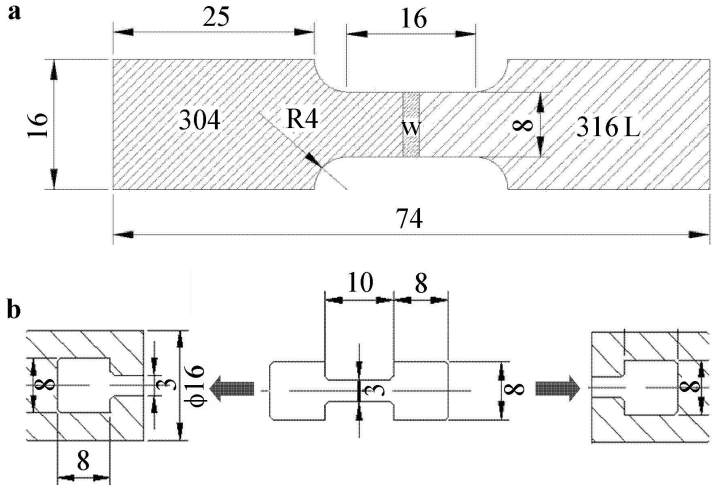

Fig. 2 The dimensions of tensile specimen (mm). a Static tensile; b Dynamic tensile

\section{Results and discussion}

\subsection{Microstructural characteristics}

The microstructure of specimen No.5 is shown in Fig. 3. The interface between the 304 base metal and the weld metal is shown in Fig. 3a. Close to the fusion boundary, the 304 region consisted of a narrow zone $(\leq 20 \mu \mathrm{m})$ of fine dendrites of ferrite and austenite. The weld metal close to this fusion boundary had a cellular structure while the weld metal at the 316 L side has worn-like structure as depicted in Figs. 3a and $3 \mathrm{~b}$. The microstructure feature of the weld metal, observed in the regions about $200 \mu \mathrm{m}$ from the fusion boundary of 304 and $316 \mathrm{~L}$ sides, is shown in Fig. 3c. It could be noticed that ferrite content decreases from 304 to $316 \mathrm{~L}$ side. a

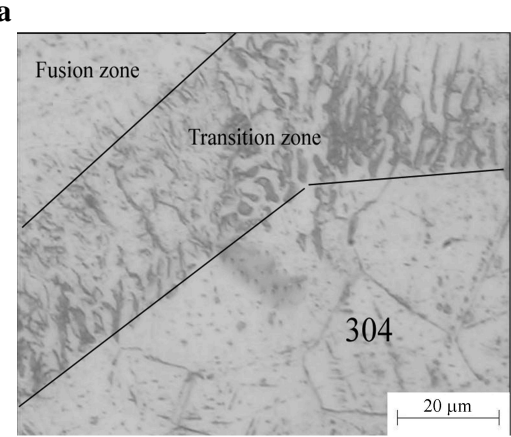

b

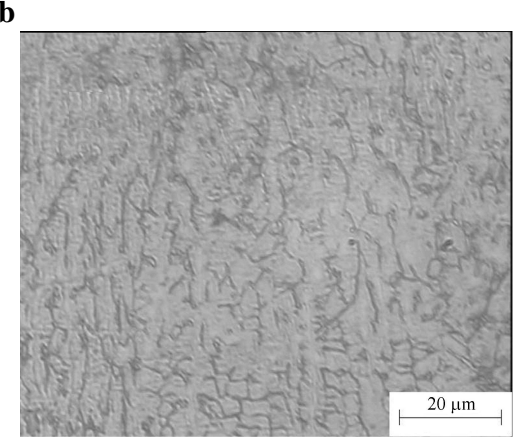

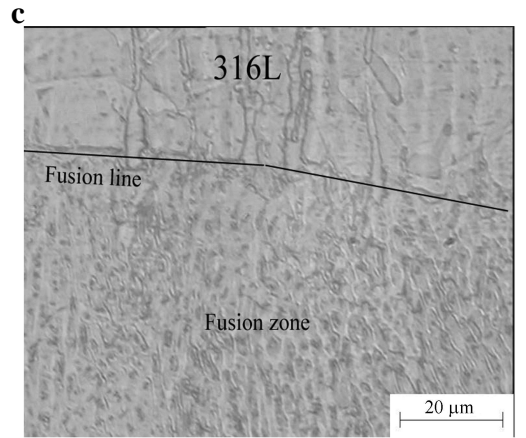

Fig. 3 a Microstructure of the 304 side; b Microstructure of the welded zone; c Microstructure of the $316 \mathrm{~L}$ side

\subsection{Microhardness}

Microhardness tests were performed on the polished sectional surface of the laser welded zone by using a load of $100 \mathrm{~g}$, which is applied for duration of $20 \mathrm{~s}$. The comparative hardness profile for the test across the weld zone from $316 \mathrm{~L}$ to 304 base materials is presented in Fig. 4. The re- sults showed that the hardness of the welded zone was in between that of $316 \mathrm{~L}$ and 304 base materials. The value had no obvious variation at the heat effect zone. The comparative hardness profile for the measurements along the welded region is shown in Fig. 5. It can be seen that the hardness gradually increases from the front surface (region A) to the back surface (region B). In the case of carbon and low al- 
loy steels, the formations of bainite or martensitic phases in the weld zone promote an increase of hardness. Grain refinement and precipitation occurring during rapid solidification of the weld zone usually cause an increase in hardness. Region B being exposed to the cool air directly was cooled more quickly than region A being contacted with the laser. This causes smaller grain size in region $\mathrm{B}$ than that in region $\mathrm{A}$, which is consistent with the hardness measurements.

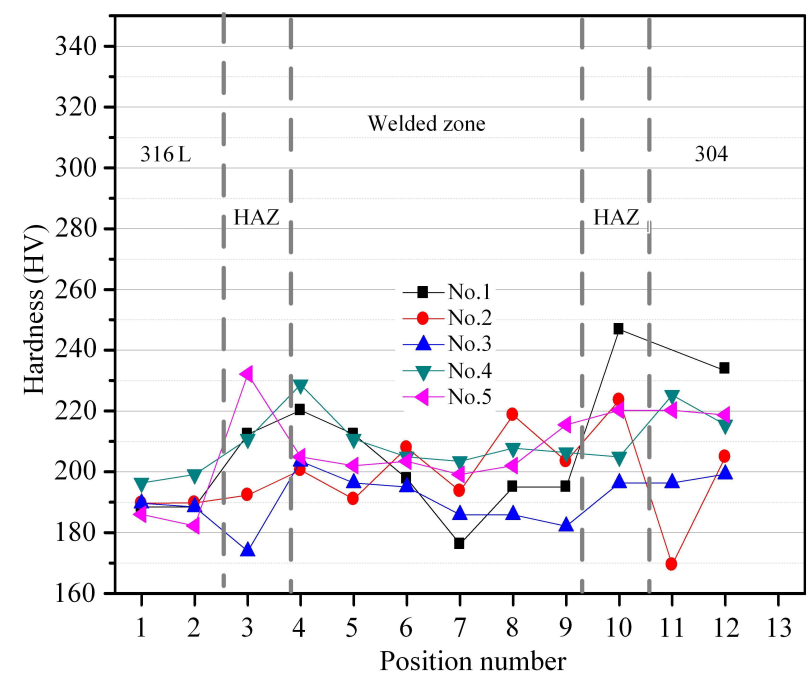

Fig. 4 The horizontal hardness of the welded joints

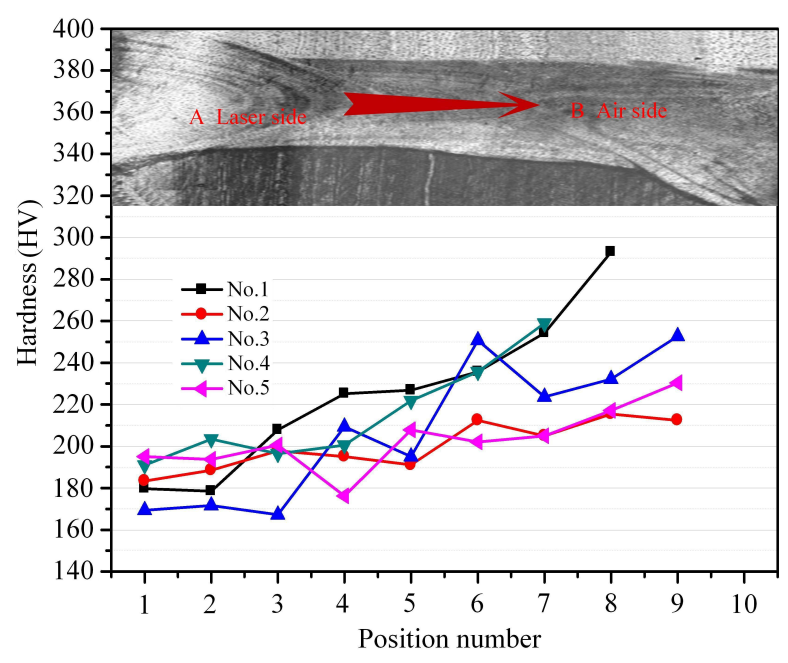

Fig. 5 The vertical hardness of the welded joints

Figure 6 showed the effect of laser power density on the average hardness which was defined as the arithmetic average hardness value of all the tested points in the weld zone. With the increase of laser power density, the average hardness raised gradually. This indicated that finer grain could be obtained by elevating the input heat in unit time and area.

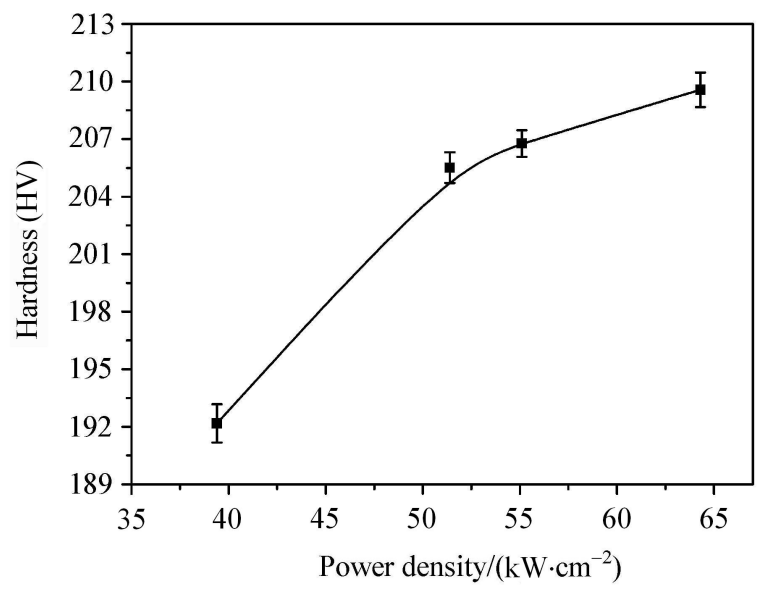

Fig. 6 The effect of laser power density on average hardness of the weld zone

\subsection{Static tensile tests}

The static tensile strain-stress curve of welded joints is shown in Fig. 7. The static yield strength, ultimate tension stress (UTS) and elongation of the welded joints were around $350 \mathrm{MPa}, 700 \mathrm{MPa}$ and $47 \%$, respectively. The fracture location was near the welded zone and at the $316 \mathrm{~L}$ side which has relative poor mechanical properties. The welded joints also inherited the fine plasticity of the base materials that is desired for the engineering designing.

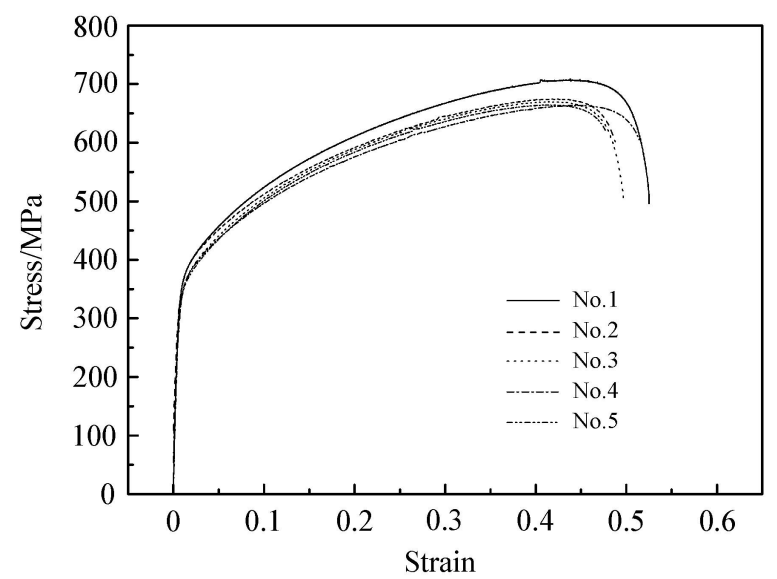

Fig. 7 The static stress-strain curve of various welding parameters

\subsection{Dynamic tensile tests}

By using the SHTB device, the dynamic tensile tests of the welded joints were carried out at strain rates $10^{3} \mathrm{~s}^{-1}$. Some specimen were broken after the test, the fracture are all located at the $316 \mathrm{~L}$ side as the same as the static tensile test. The dynamic yield strength and UTS for different laser welding parameters are shown in Table 4. It showed that the yield strength of the welded joints under dynamic loading had higher value than that of static tests. The UTS did not 
change until the strain rate reached $1600 \mathrm{~s}^{-1}$.

Table 4 Dynamic mechanical properties of the welded joints

\begin{tabular}{lllll}
\hline \multirow{2}{*}{ No. } & \multicolumn{4}{c}{$\sigma_{s}(\mathrm{UTS}) / \mathrm{MPa}$} \\
\cline { 2 - 5 } & Static & $\dot{\varepsilon}=1200 \mathrm{~s}^{-1}$ & $\dot{\varepsilon}=1600 \mathrm{~s}^{-1}$ & $\dot{\varepsilon}=1950 \mathrm{~s}^{-1}$ \\
\hline 1 & $342(706)$ & $459(693)$ & $477(734)$ & $498(962)$ \\
2 & $354(674)$ & $510(660)$ & $540(707)$ & $613(816)$ \\
3 & $341(669)$ & $428(674)$ & $470(710)$ & $589(795)$ \\
4 & $341(663)$ & $580(663)$ & $560(754)$ & $540(726)$ \\
5 & $333(664)$ & $450(650)$ & $480(650)$ & $520(721)$ \\
\hline
\end{tabular}

Typical dynamic stress-strain curves are shown in Fig. 8. It is worth noting that the waveness in the dynamic strain-stress curve is caused by the stress wave reflection at the connection interface between specimen and the elastic

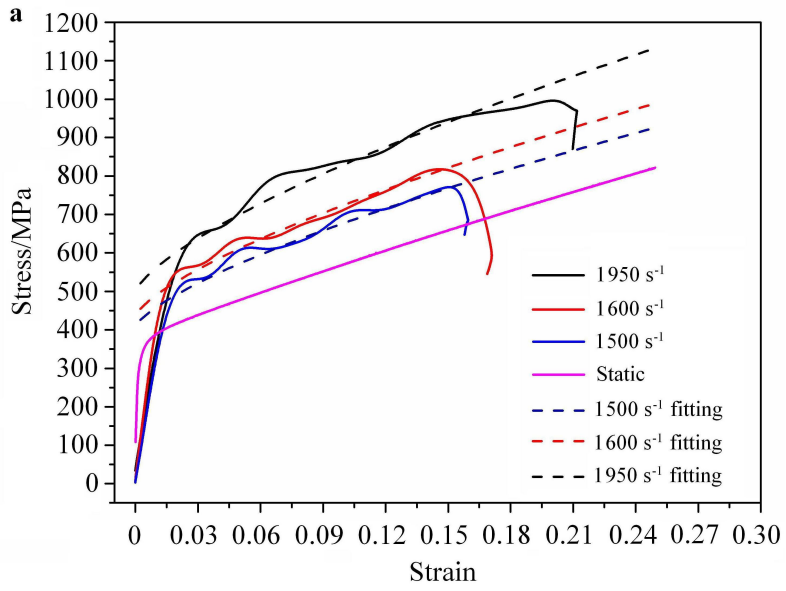

Fig. 8 The dynamic stress-strain curve of a No.2; b No.4

The strain rate factor $\beta$ is often used to characterize the strain rate sensitivity of the plastic flow stress [20], which is carried out to measure the effect of the strain rate of various welded joints,

$\beta=\frac{\partial \sigma}{\partial \ln \dot{\varepsilon}}=\frac{\sigma_{2}-\sigma_{1}}{\ln \left(\dot{\varepsilon}_{2} / \dot{\varepsilon}_{1}\right)}$,

where $\sigma_{1}$ and $\sigma_{2}$ are plastic flow stresses of the uniform strain state at various strain rates $\dot{\varepsilon}_{1}$ and $\dot{\varepsilon}_{2}$, respectively. Figure 9 shows the strain rate factor $\beta$ of different welding parameters at the same strain level 3\%,6\%, 9\%, 12\% and $15 \%$. It shows that the value of $\beta$ had an upward trend as the strain increases. This indicates that the welded joint is more sensitive to the strain rate at larger strain. However, there were differences in $\beta$ for different welding parameters. For specimens No.1 and No.2, it varies between 20-30 while for specimens No.3 and No.5, it varies between -5-5. It implied that the joint with low laser power density has higher strain rate sensitivity and is able to endure higher plastic flow stress at elevated strain rates. For the joint with high laser power bar rather than the real mechanical response of welded joints themselves. Moreover, the stress non-uniformity because of reflection of the stress wave at initial deformation stage may be reinforced by the SHTB slot. So, the Young's modulus can not be captured exactly in this experiment. To further study the effect of strain rates on the average flow stress for different welding parameters, Johnson-Cook model is applied here to fit the dynamic strain-stress curve of welded joints

$\sigma=\left(A+B \varepsilon^{n}\right)\left(1+C \ln \dot{\varepsilon}^{*}\right)$,

where $A, B$ and $n$ are static mechanical parameters which can be derived from the static strain-stress curve. $\dot{\varepsilon}^{*}=\dot{\varepsilon} / \dot{\varepsilon}_{0}$ is the dimensionless strain rate, $\dot{\varepsilon}_{0}=1 / s, C$ is the strain rate hardening parameters. The fitting results are also included in Fig. 8, the variation caused by stress wave propagation was mostly removed from the dynamic strain-stress curve.

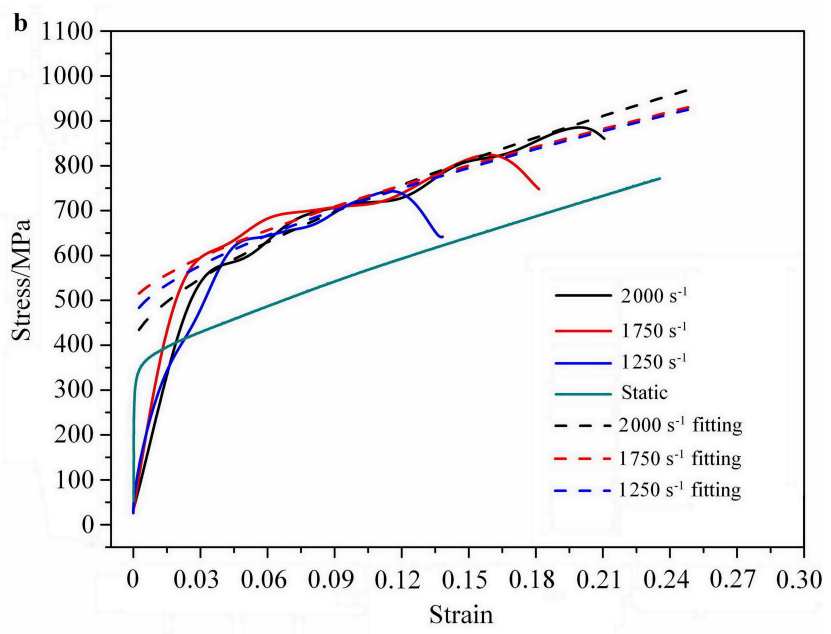

density, strain rate weakening appears at the initial deformation stage, and minor strain rate hardening does not occur until the strain reached $9 \%$. Strain rate weakening exists in

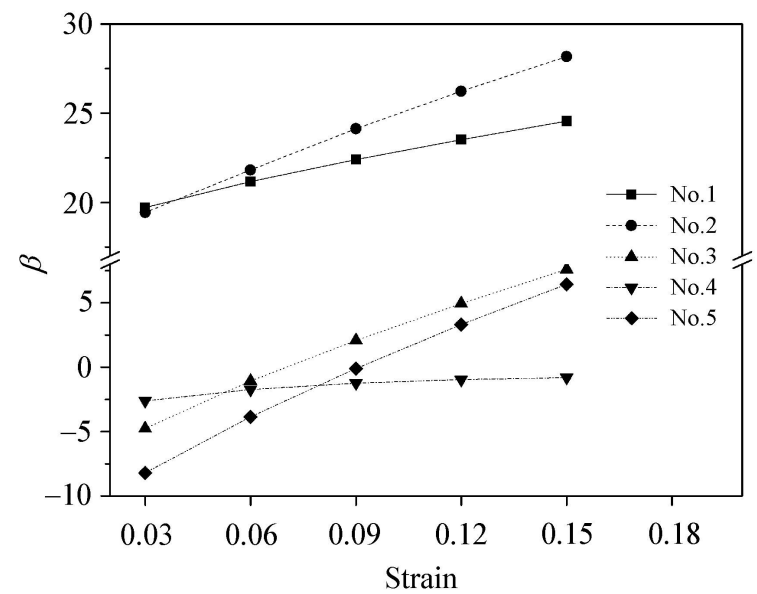

Fig. 9 The $\beta$ of the welded joints at different deformation stage 
any stage of deformation of specimen No.4, which is desired for high strain rate conditions.

The dependence of average values of $\beta$ on the laser power density is shown in Fig. 10. It was found that laser power density had significant effect on the strain rate factor. Average values of $\beta$ has a decreasing trend with the increase of power density except a slight increase at the tail. It seemed that there is a sharp transition from strain rate hardening to weakening around laser power density of $45 \mathrm{~kW} / \mathrm{cm}^{2}$. It can be inferred that, in the case of welding quality assurance, the ability of welded joints to withstand impact loading can be improved by reducing the laser welding power density.

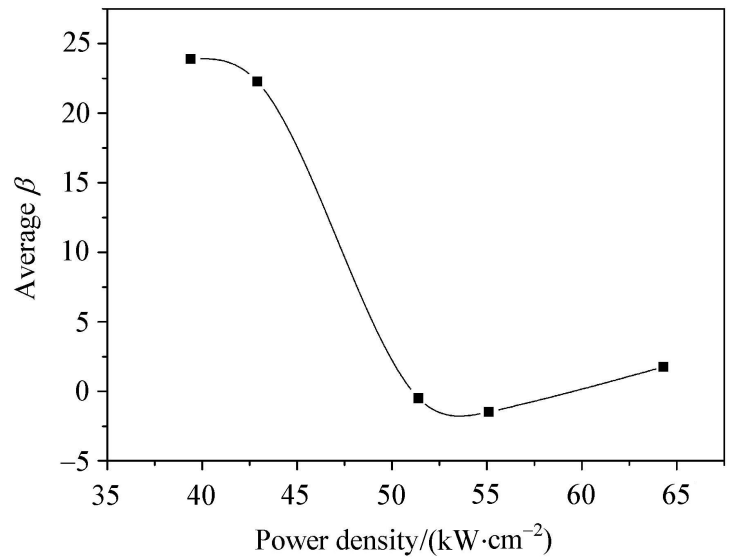

Fig. 10 The effect of laser power density on average $\beta$

\section{Conclusions}

The main conclusions are as follows:

(1) The dynamic stress-strain curves of the welded joints were obtained at the strain rates $10^{3} \mathrm{~s}^{-1}$ by an improved SHTB device. The strain rate factor $\beta$ was calculated from the stress-strain curve at different deformation stages. It was found that the value of $\beta$ for various welding parameters increases with the increase of the strain.

(2) Laser power density has less effect on static mechanical properties of welded joints. However, in the case of impact loading, the strain rate sensitivity depends on laser power density. The value of $\beta$ decreases dramatically with increasing laser power density.

(3) The ability of welded joints to withstand impact loading could be improved by reducing the laser welding power density in the case of welding quality assurance.

\section{References}

1 Schmitt, J.H.: Some examples of stainless steel use in the automotive industry. Advanced Materials Forum I, Key Engineer- ing Materials 230-232, 17-22 (2002)

2 Santacreu, P.O., Glez, J.C., Chinouilh, G., et al.: Behaviour model of austenitic stainless steels for automotive structural parts. Steel Research International 9, 686-691 (2006)

3 Hariharan, K., Balachandran, G., Prasad, M.S.: Application of cost-effective stainless steel for automotive components. Materials and Manufacturing Processes 12, 1442-1452 (2009)

4 Heubner, U.: High-alloyed corrosion resistant steels for the chemical process industry, power engineering and marine technology - past and future. Materials and Corrosion 10, 756764 (2002)

5 Anoop, M.B., Rao, K.B., Lakshmanan, N.: Safety assessment of austenitic steel nuclear power plant pipelines against stress corrosion cracking in the presence of hybrid uncertainties. International Journal of Pressure Vessels and Piping 4, 238-247 (2008)

6 Earvolino, L., Kennedy, J.: Laser welding of aerospace structural alloys. Welding Journal 45, 127-134 (1966)

7 Mazumder, J.: Laser-welding-State of the art review. Journal of Metals 7, 16-24 (1982)

8 Steen, W.M.: Laser material processing: an overview. Journal of Optics A: Pure and Applied Optics 4, S3-S7 (2003)

9 Bayraktar, E., Kaplan, E., Buirette, C., et al., Application of impact tensile testing to welded thin sheets. Journal of Materials Processing Technology 145, 27-39 (2004) DOI: 10.1016/S0924-0136(03)00859-8

10 Bayraktar, E., Kaplan, D., Grumbach, M.: Application of impact tensile testing to spot welded sheets. Journal of Materials Processing Technology 153, 80-86 (2004)

11 Bayraktar, E., Kaplan, D., Schmidt, F., et al.: State of art of impact tensile test (ITT): Its historical development as a simulated crash test of industrial materials and presentation of new "ductile/brittle" transition diagrams. Journal of Materials Processing Technology 204, 313-326 (2008)

$12 \mathrm{Xu}, \mathrm{Z} ., \mathrm{Li}, \mathrm{Y}$ : Dynamic behaviors of Cr18Ni10Ti stainless steel welded joints at elevated temperatures and high strain rates. Mechanics of Materials 41, 121-130 (2009)

13 Chen, S.Y., Huang, C.G., Lan, T.: Real-time observations on deformation and failure of LY12 samples under impact tension. Key Engineering Materials 345, 1145-1148 (2007)

14 Song, W., Liu, H., Ning, J.: Mechanical property and numerical simulation on W-Ni-Fe alloys. Chinese Journal of Theoretical and Applied Mechanics 42, 1149-1155 (2010) (in Chinese)

$15 \mathrm{Xu}, \mathrm{Z} . J .$, Li, Y.L.: Dynamic fracture toughness of high strength metals under impact loading: increase or decrease. Acta Mech. Sinica 27, 559-566 (2011)

16 Xu, Z.J., Li, Y.L.: Dynamic fracture toughness of high strength metals under impact loading: increase or decrease. Acta Mech. Sinica 27, 559-566 (2011)

17 Johnson, G.R., Cook, W.H.: A constitutine model and data for metals subjected to large strains, high strains rates, and high temperature. In: Proceedings of Seventh International Symposium on Ballistics, Netherlands, 541-547 (1983) 